\title{
Construction area expansion in relation to economic-demographic development and land resource in the Pearl River Delta of China
}

\author{
LIU Zhijia ${ }^{1,2},{ }^{*}$ HUANG Heqing ${ }^{1}$, Saskia E. WERNERS ${ }^{3}$, YAN Dan ${ }^{3}$
}

1. Institute of Geographic Sciences and Natural Resources Research, CAS, Beijing 100101, China;

2. University of Chinese Academy of Sciences, Beijing 100049, China;

3. Earth Systems Science - Climate Change Group, Wageningen University and Research Centre, Box 47, 6700 AA Wageningen, The Netherlands

\begin{abstract}
Since 1979, the Pearl River Delta (PRD) of China has experienced rapid socioeconomic development along with a fast expansion of construction area. Affected by both natural and human factors, a complex interdependency is found among the regional changes in construction area, GDP and population. A quantitative analysis of the four phases of the regional land use data extracted from remote sensing images and socioeconomic statistics spanning 1979 to 2009 demonstrates that the proportion of construction area in the PRD increased from $0.5 \%$ in 1979 to $10.8 \%$ in 2009 , accompanied with a rapid loss of agricultural land. An increase of one million residents was associated with an increase of GDP of approximately 32 billion yuan before 2000 and approximately 162 billion yuan after 2000 . Because the expansion of construction area has approached the limits of land resource in some cities of the PRD, a power function is found more suitable than a linear one in describing the relationship between GDP and construction area. Consequently, the Logistic model is shown to provide more accurate predictions of population growth than the Malthus model, particularly in some cities where a very large proportion of land resource has been urbanized, such as Shenzhen and Dongguan.
\end{abstract}

Keywords: construction area expansion; GDP growth; population growth; land resource; Pearl River Delta

As a hub of human population, urban land is strongly affected by the socioeconomic activities of the residents. Since the mid-20th century, the global expansion of urban land has exhibited an accelerating trend, especially in developing countries and regions (Davis 1966; Hance, 1970; World Resources Institute, 1996; Seto et al., 2003; Deng et al., 2008). Influenced by population growth, economic development, natural environment and their interac-

Received: 2015-04-03 Accepted: 2015-08-27

Foundation: China-Netherlands Joint Research Project of Chinese Academy of Sciences, No.GJHZ1019; National Natural Science Foundation of China, No.41330751

Author: Liu Zhijia (1986-), PhD Candidate, specialized in simulation of land use and cover change (LUCC). E-mail: krasovsky@163.com

*Corresponding author: Huang Heqing (1962-), PhD and Professor, E-mail: huanghq@igsnrr.ac.cn 
tions, urban land expansion exhibits characteristics of complex systems (Li et al., 2000; Portugali, 2000; Filatova et al., 2009; Bettencourt, 2013).

Among the contributing factors, socioeconomic development plays a dominant role in urban land expansion (World Resources Institute, 1996; Henderson, 2003; Seto et al., 2011). In most cases, urban land expansion is closely related to economic growth (Zhou 1982; Moomaw et al., 1996; Henderson, 2003; Tan et al., 2003; Bertinelli et al., 2004; Liu et al., 2005; Seto et al., 2011; Chen, 2011). Nevertheless, this relationship differs from one place to another and in some regions urban land expansion is not always synchronized with economic growth. There are many cases in which construction area expansion continues while the regional economy stagnates or declines (Fay et al., 2000; Chang et al., 2006). In addition, population growth and concentration have dual effects on construction area expansion. At a lower population density, increasing population can accelerate construction area expansion. When the population density increases to a certain degree, urban congestion and environmental degradation appear, leading to a negative effect on construction area expansion (Davis, 1966; Hance, 1970; Ottensmann, 1977; Oucho et al., 1993; Sato et al., 2005; Deng et al., 2008). This complex feedback effect of construction area expansion on economic and population growth makes it difficult to predict the future of urban development (Hu, 2003; Sato et al., 2005; Cheng, 2007; Shen et al., 2007).

Having been experiencing more than 30 years of rapid development, the Pearl River Delta (PRD) becomes one of the most developed regions in China. To understand the interrelationships among economic development, population growth and construction area expansion in the region will help to enhance our knowledge on the mechanisms and trends of the regional urban land expansion, and consequently provide a sample and reference for sustainable urban development in other regions.

\section{The study area}

The Pearl River Delta (PRD) is located in the central and southern Guangdong Province of China, including nine prefecture-level cities: Guangzhou, Shenzhen, Zhuhai, Dongguan, Foshan, Zhongshan, Jiangmen, Huizhou, and Zhaoqing (Figure 1). The total area of the PRD is approximately $5.49 \times 10^{4} \mathrm{~km}^{2}$. With a subtropical monsoon climate and fertile soil, crops are harvested two or three times each year, making the PRD an important crop production base of China. The dominant crop in the region is rice, and the other major crops

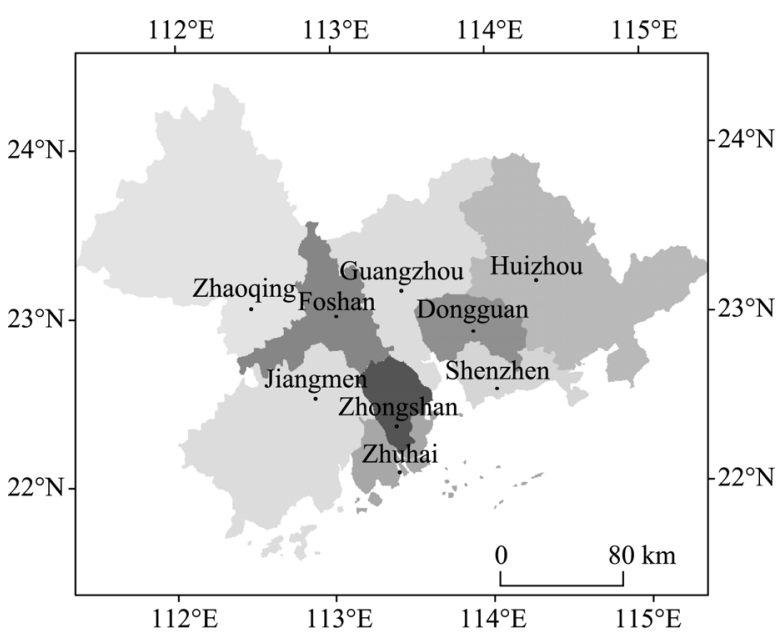

Figure 1 Location of the Pearl River Delta of China are sugar cane, peanuts, soybeans, bananas, oranges and lychees.

Shortly after China's economic reform at the beginning of the 1980 s, with an attempt to 
attract foreign investment and accelerate economic development, two special economic zones, Shenzhen and Zhuhai, adjacent to Hong Kong and close to Macao respectively, were established in the PRD. With preferential tax policies and other favorable policies, the economy of the two special zones has grown at a high speed over the last 30 years, stimulating the economic development of the entire PRD. As a result, the GDP in the PRD grew more than 70 times from 1979 to 2009, at an annual average growth rate of $15.36 \%$ (at comparable prices in 2000). Along with the economic growth, a large number of employment opportunities have been created, attracting a large migrant population into the PRD. There were more than 23 million migrants living in the PRD in 2009, accounting for more than $40 \%$ of the total resident population in the region. Most migrants are concentrated in Shenzhen, Guangzhou, Dongguan and Foshan. At the same time, the industrial structure in the PRD has undergone great changes. From 1979 to 2009, the proportion of the primary industry dropped to $2.3 \%$ from $26.8 \%$, and the proportion of the tertiary industry increased from $27.6 \%$ to $49.8 \%$, although the proportion of the secondary industry remained relatively stable, fluctuating between $45 \%-50 \%$. Along with the rapid economic and population growth, land use in the PRD has undergone a tremendous change and the dominant form is the rapid expansion of construction area (Seto and Kaufmann 2003).

\section{Spatiotemporal expansion of construction area in the PRD}

\subsection{Data sources and preprocessing}

To generate the time-series of land use data in the PRD, we selected Landsat images taken in an approximate 10-year interval from 1979. The earliest images taken in 1979 have a 57-m spatial resolution acquired with the Landsat Multispectral Scanner (MSS), while the other images taken in 1990, 1999 and 2009 have a 30-m spatial resolution acquired with the Landsat Thematic Mapper (TM) or Enhanced Thematic Mapper (ETM). The images in 1989 have a high degree of cloud cover and so they are replaced by the images in 1990. All images were downloaded from the U.S. Geological Survey (USGS) website (USGS 2012).

The main reference for the classification of the remote sensing images is the China's national standard of "Current Land Use Classification" (General Administration of Quality Supervision 2007). In the classification, residential land, transportation land, warehouse land for mines, and land for public administration and public services are merged into construction land, forming the metric of urban area change in the PRD.

The images were interpreted in ENVI by a supervised classification method, in which the training samples were defined by a visual interpretation based on the pseudo-color display $(\mathrm{RGB}=5,4$ and 3). To aid the visual interpretation, high-resolution images from Google Earth were used. In the selection of the training samples from the images taken in 1999 and 2009, we found many available Google Earth images, which are beneficial to improve the reliability of the samples. However, only a small number of Google Earth images are available in 1979 and 1990, and so the classification result obtained for 1999 were used as a reference. These classification results are presented in Figure 2. 


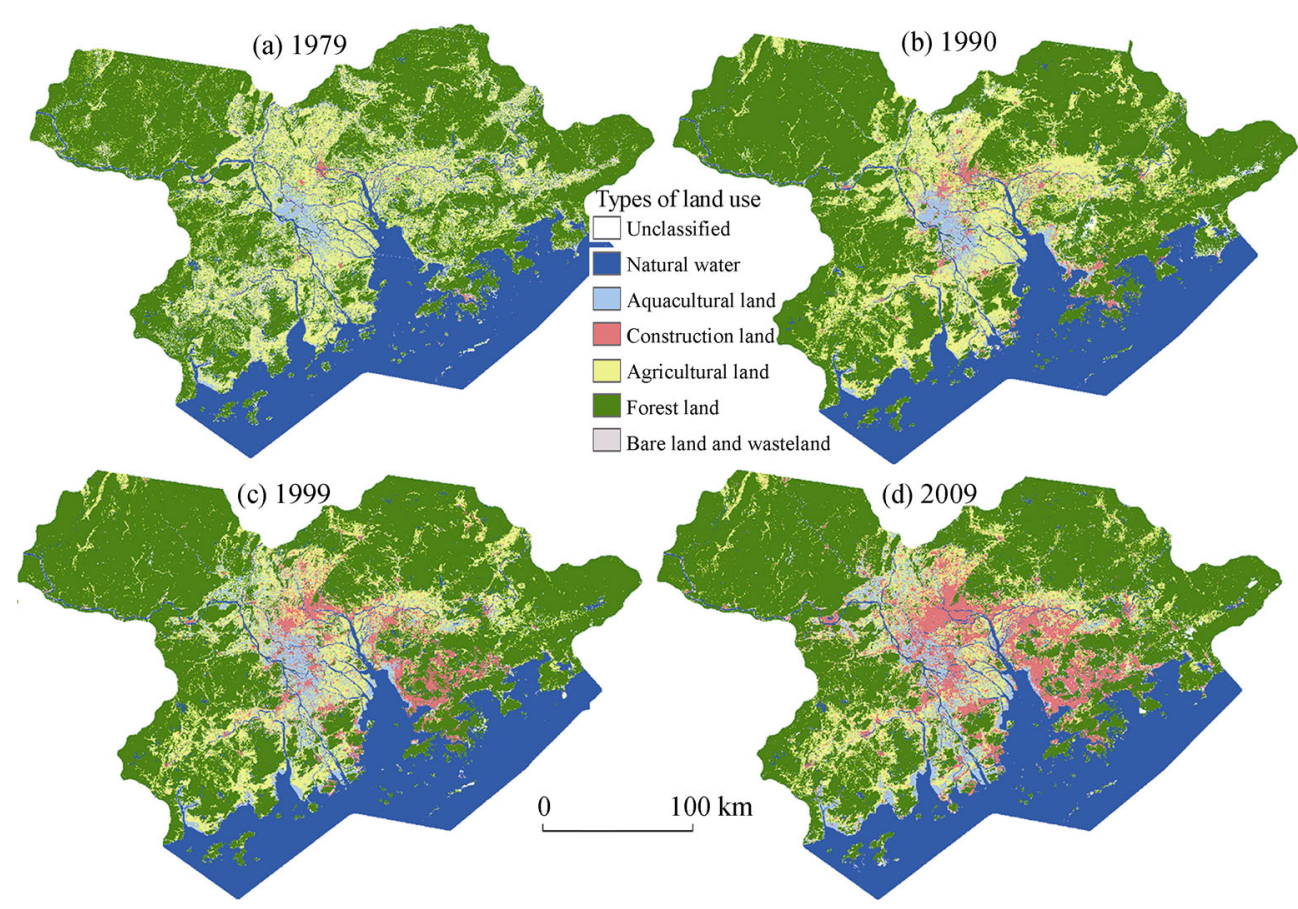

Figure 2 Land use changes in the Pearl River Delta during 1979-2009

Commission and omission errors are inevitable in remote sensing classifications. To obtain the actual ROI (Region of Interest) in each land use classification, both field validation and visual interpretation based on Google Earth high-resolution images were conducted. A field survey was implemented in the representative sites of Guangzhou, Foshan, Zhongshan and Zhaoqing to verify the classification, in addition to the verification with Google Earth images that have a resolution of up to $1 \mathrm{~m}$. Based on the ROIs of actual land use types and the classification results, the corresponding confusion matrixes were calculated in ENVI.

It is noticeable in Table 1 that the degree of commission errors in construction land is lower, but the degree of omission errors is higher. This is due to the difficulty in distinguishing the area of green belt. The green belt in construction land is very close to agriculture land and forestry in spectrum and prone to being classified as farmland or forestry by mistake. In the other parts of construction land, both commission and omission errors are much lower, and so the user accuracy of construction land in 2009 and 1999 reaches as high as about $93 \%$. In 1990, the clouds in the images descend the user accuracy of construction land to $89 \%$. Because of the concentration of construction land, the accuracy loss of construction land classification caused by the lower resolution of images in 1979 is smaller than that of other land use type, and the user accuracy of construction land still reaches $82 \%$ in 1979.

\subsection{Spatiotemporal characteristics of construction area expansion}

A detailed statistical analysis of the land use data in the four phases (1979, 1990, 1999 and 2009) reveals that the area of construction land in the PRD was $246.58 \mathrm{~km}^{2}$ in 1979 , accounting for only approximately $0.5 \%$ of the total land area. In 2009 , the area of construc- 
tion land expanded to $5844.58 \mathrm{~km}^{2}$, and its proportion in the total land area rose to $10.8 \%$. However, this significant expansion of construction area has taken different paces during the three periods, with an expansion of $986.00 \mathrm{~km}^{2}$ in $1979-1990,1886.25 \mathrm{~km}^{2}$ in $1990-1999$, and $2725.75 \mathrm{~km}^{2}$ in $1999-2009$, respectively.

Table 1 Confusion matrix of classification for the Pearl River Delta in 2009

\begin{tabular}{|c|c|c|c|c|c|c|c|}
\hline & & & & Actual & d use & & \\
\hline & Pixel count & $\begin{array}{c}\text { Natural } \\
\text { water }\end{array}$ & $\begin{array}{l}\text { Aquacultural } \\
\text { land }\end{array}$ & $\begin{array}{c}\text { Construction } \\
\text { land }\end{array}$ & $\begin{array}{l}\text { Agricultural } \\
\text { land }\end{array}$ & $\begin{array}{c}\text { Forest } \\
\text { land }\end{array}$ & $\begin{array}{c}\text { Bare land and } \\
\text { wasteland }\end{array}$ \\
\hline & Unclassified & 1 & 1 & 166 & 9 & 84 & 25 \\
\hline & Natural water & 35491 & 5333 & 7 & 2 & 6 & 0 \\
\hline. & Aquacultural land & 2366 & 10739 & 71 & 125 & 19 & 0 \\
\hline 包 & Construction land & 135 & 331 & 21579 & 650 & 359 & 135 \\
\hline 足 & Agricultural land & 21 & 248 & 2532 & 19798 & 3060 & 108 \\
\hline & Forest land & 0 & 2 & 94 & 504 & 39705 & 8 \\
\hline & $\begin{array}{l}\text { Bare land and- } \\
\text { wasteland }\end{array}$ & 0 & 3 & 1793 & 59 & 221 & 2614 \\
\hline & & & & Actual & d use & & \\
\hline Per & ntage $(\%)$ & $\begin{array}{c}\text { Natural } \\
\text { water }\end{array}$ & $\begin{array}{l}\text { Aquacultural } \\
\text { land }\end{array}$ & $\begin{array}{c}\text { Construction } \\
\text { land }\end{array}$ & $\begin{array}{l}\text { Agricultural } \\
\text { land }\end{array}$ & $\begin{array}{l}\text { Forest } \\
\text { land }\end{array}$ & $\begin{array}{c}\text { Bare land and } \\
\text { wasteland }\end{array}$ \\
\hline & Unclassified & 0 & 0.01 & 0.63 & 0.04 & 0.19 & 0.87 \\
\hline & Natural water & 93.36 & 32.02 & 0.03 & 0.01 & 0.01 & 0 \\
\hline ฮే & Aquacultural land & 6.22 & 64.47 & 0.27 & 0.59 & 0.04 & 0 \\
\hline 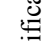 & Construction land & 0.36 & 1.99 & 82.23 & 3.07 & 0.83 & 4.67 \\
\hline 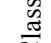 & Agricultural land & 0.06 & 1.49 & 9.65 & 93.62 & 7.04 & 3.74 \\
\hline & Forest land & 0 & 0.01 & 0.36 & 2.38 & 91.37 & 0.28 \\
\hline & $\begin{array}{l}\text { Bare land and } \\
\text { waste land }\end{array}$ & 0 & 0.02 & 6.83 & 0.28 & 0.51 & 90.45 \\
\hline Use & accuracy & 86.90 & 80.62 & 93.06 & 76.83 & 98.49 & 55.74 \\
\hline
\end{tabular}

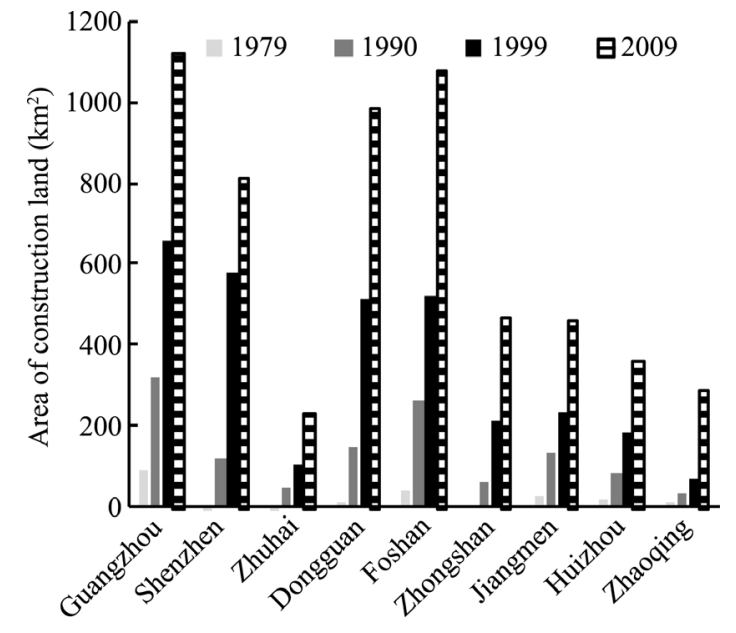

Figure 3 Construction area changes in each city of the Pearl River Delta (1979-2009)
As shown in Figures 3 and 4, the areas and proportions of construction land vary significantly with time in different cities. In Shenzhen and Dongguan, the proportions of construction land were less than $1 \%$ before the economic reform. Since then, the areas of construction land in the two cities have expanded much more sharply than in the other cities, and the construction land proportions in both cities rose to more than $40 \%$ in 2009 , much higher than in the other cities. In Guangzhou and Foshan, the areas and proportions of construction land were significantly higher than in the other cities in 1979, and the areas of their con- 
struction land were still the top two among the nine cities in 2009. However, the overall proportions of their construction land were significantly lower than in Shenzhen and Dongguan due to the relatively slower rates of construction land expansion and the imbalanced internal development in the two cities. For small cities in the PRD, typically Zhuhai and Zhongshan, their construction land areas were relatively smaller, while the proportions of their construction land were close to Guangzhou and Foshan. Because Jiangmen, Huizhou and Zhaoqing are located at the edge of the region, the areas of their construction land were approximately

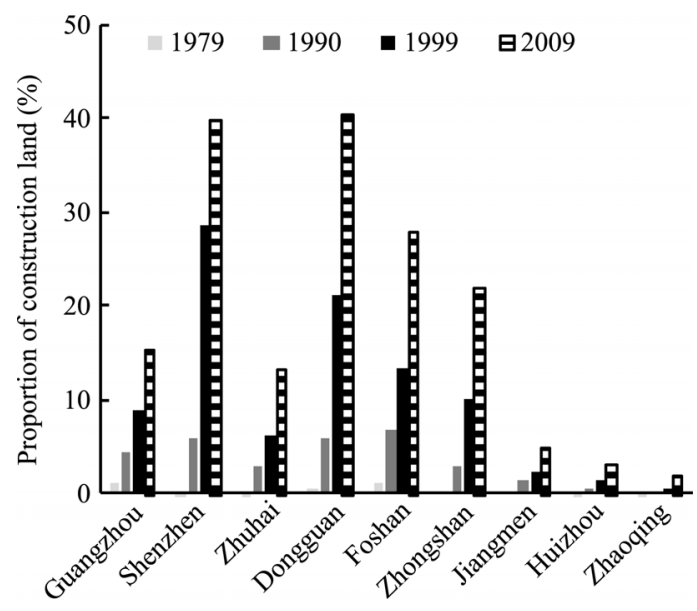

Figure 4 Changes in the proportion of construction land in each city of the Pearl River Delta (1979-2009) equivalent to those in Zhuhai and Zhongshan, and yet the proportions of their construction land were much smaller than in the other six cities.

It can also be noticed in Figures 3 and 4 that the rapid expansion of construction land in Shenzhen and Dongguan has changed the distributing pattern of construction land in the entire PRD region. In 1979, 57.33\% of the construction land in the region was concentrated in Guangzhou and Foshan. In 2009, the proportions of the total construction land in the two cities fell to $37.78 \%$, while the proportions of the total construction land in Shenzhen and Dongguan rose from $7.26 \%$ in 1979 to $30.90 \%$ in 2009 .

\section{Spatiotemporal characteristics of economic and population changes}

\subsection{Changes in GDP and resident population}

The statistics on the GDP and resident population in the PRD mainly came from the statistical yearbook of each city and the Guangdong Province Statistical Yearbook. Before 1990,

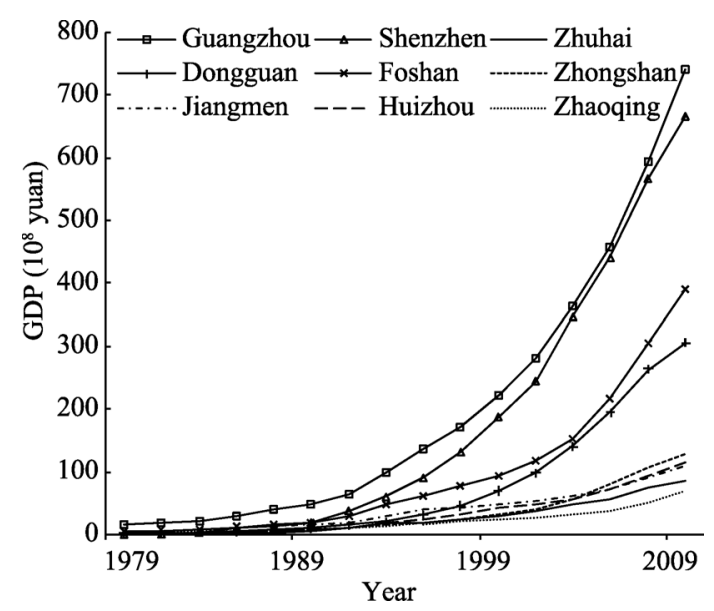

Figure 5 Changes of GDP in each city of the Pearl River Delta (1979-2009) there was no resident population data for some cities, and so the household population data are used to approximate the resident population data. All of the GDP data are adjusted according to the comparable prices in 2000. Based on the comparable prices, GDP of the PRD has grown 71.73 times from 1979 to 2009 , at an annual average rate of $15.36 \%$ (Figure 5). The resident population in the same period has grown 1.96 times, at an annual average rate of $3.69 \%$ (Figure 6 ).

During 1979 to 2009, the annual GDP growth rate in the PRD remained predomi- 
nantly above $10 \%$, with only a few exceptions, while the annual population growth rate in the region was relatively lower and varied in different stages. In the 1980s, the growth rate of resident population was approximately $2 \%$. In the 1990 s, driven by the rapid growth of resident population in Shenzhen and Dongguan, the annual growth rate of resident population in the entire region increased to $6-8 \%$, and the total resident population nearly doubled within a decade. From 2000 to 2005, the annual growth rate of resident population decreased significantly except in Shenzhen,

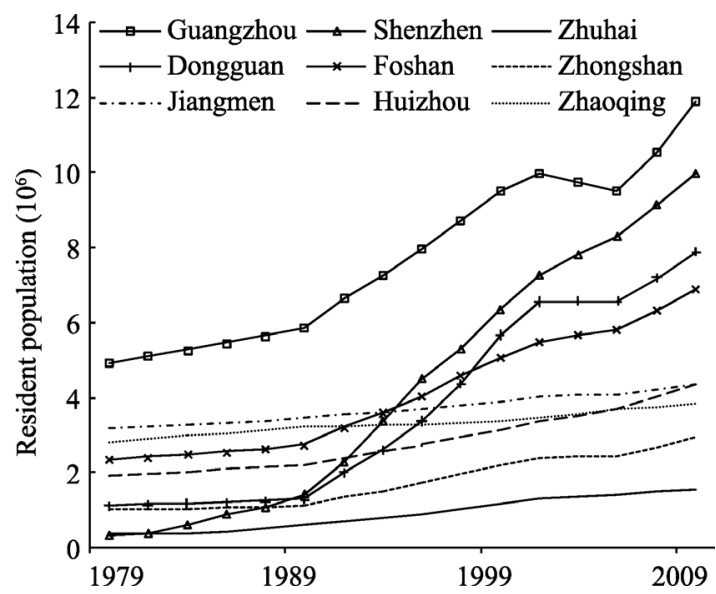

Figure 6 Resident population changes in each city of the Pearl River Delta (1979-2009) with the population growth rate in the whole PRD region falling below 2\%. It was only after 2005 that the growth rate of resident population in the region began to recover gradually to over $4 \%$.

The annual average growth rates of GDP and resident population in each city of the PRD have also varied significantly. Shenzhen and Dongguan have experienced the most rapid increases in the past three decades, while the annual growth rates of GDP and resident population in Guangzhou, Foshan, Zhuhai, and Zhongshan were close to the average growth rates of the whole region. In contrast, Jiangmen, Huizhou and Zhaoqing took significantly lower rates than the regional averages in both GDP and resident population.

\subsection{Correlation between GDP and resident population}

Economic development and population growth are related closely. Rapid economic development attracts migrants and the influx of migrants provides cheap labor for economic development, promoting economic prosperity in return (Yang 1995; Chen 2008). The growth of GDP in relation to the increase of resident population in the PRD is shown in Figure 7. It

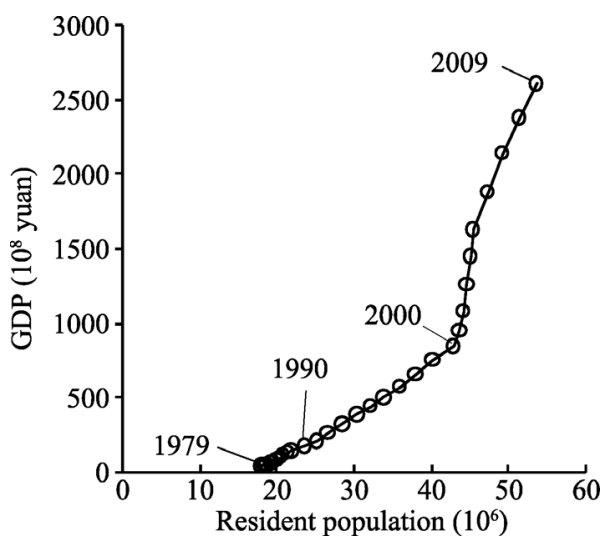

Figure 7 Relationship between GDP and resident population in the Pearl River Delta (1979-2009) can be noticed that the relationship between GDP and resident population in the region is not a simple linear relationship; there was a clear turning point around 2000. Before 2000, GDP increased by approximately 32 billion yuan with each increase of one million in the resident population. After 2000, an equivalent increase of resident population contributed to an increase of approximately 162 billion yuan in GDP. As a result, the per capita GDP increased year by year in the PRD. In 1979, the per capita GDP was approximately 2,000 yuan; it increased to 19,600 yuan in 2000 . Since 2000, the per capita GDP has accelerated significantly and reached 48,700 yuan in 2009 . 


\section{Relationships between construction area, GDP and resident population}

\subsection{Linear relationships}

To quantitatively understand the relationships between construction area expansion with changes in GDP (at comparable prices in 2000) and resident population, a linear regression model is applied to all cities in the PRD during 1979-2009 and the results are presented in Table 2. It is noticeable from Table 2 that the linear relationships between construction area, GDP and resident population are both significant. The value of coefficient $b_{1}$ means that for $1 \mathrm{~km}^{2}$ of the construction area expansion, the regional GDP increases by approximately 0.4761 billion yuan and the resident population increases by approximately 7600 . These significant correlations between construction area, GDP and resident population are closely related to the constitution of construction land. According to the statistics, the shares of industrial land and residential land are the two highest in the construction land (Deng et al., 2008). The expansion of industrial land, accompanying with expansion of industrial production scale and growth of industrial output, can promote significantly a city's growth in GDP. In the same tune, the growth of resident population generates a significant demand for residential land, stimulating the development of more residential land.

Table 2 Regression relationships of construction area with GDP and population in the Pearl River Delta

\begin{tabular}{ccccc}
\hline & \multicolumn{2}{c}{ Linear regression model } & Power function regression model \\
\cline { 2 - 5 } & GDP $\left(10^{9}\right.$ yuan $)$ & $\begin{array}{c}\text { Resident population } \\
\left(10^{6}\right)\end{array}$ & Log (GDP) & $\begin{array}{c}\text { Log (resident } \\
\text { population) }\end{array}$ \\
\hline$b_{0}$ & -39.1430 & 1.5385 & -2.1228 & -1.1565 \\
$b_{1}$ & 0.4761 & 0.0076 & 1.1119 & 0.4502 \\
$R^{2}$ & 0.7585 & 0.7563 & 0.9257 & 0.7032 \\
$F$ & 106.78 & 94.24 & 423.80 & 80.55 \\
$F(0.05)$ & 4.13 & 4.13 & 4.13 & 4.13 \\
Standard coefficient & 0.87 & 0.87 & 0.96 & 0.84 \\
$T$ test value & 10.48 & 10.42 & 20.89 & 9.11 \\
$t(0.05)$ & 2.03 & 2.03 & 2.03 & 2.03 \\
\hline
\end{tabular}

\subsection{Nonlinear relationships}

Figure 8 is plotted with the data of construction area against GDP data in all nine cities of the PRD and it is clear that the plots are not evenly distributed along both sides of the linear regression curve. Figure 9 presents the regression relationship between construction area and resident population in all nine cities of the PRD and it can be noticed that the data points are relatively evenly distributed along both sides of the linear regression curve. To improve the accuracy of the relationships, several nonlinear regression models are examined and it is found that the value of $R^{2}$ of the power-function regression model between GDP and construction

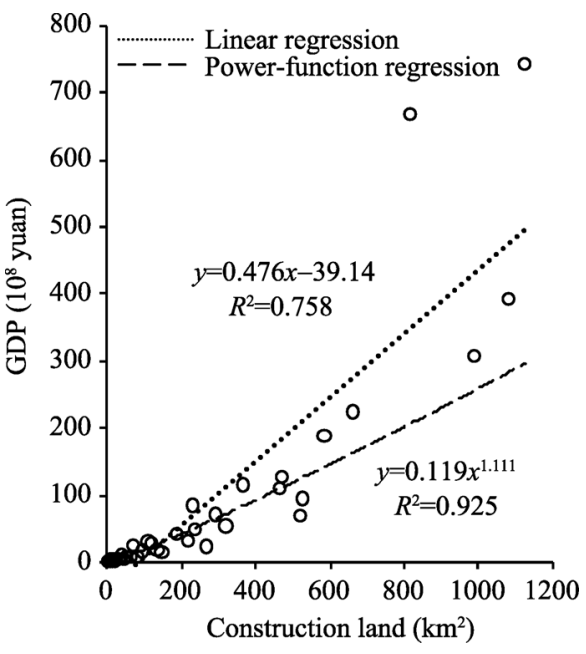

Figure 8 Relationship between GDP and construction land area in the Pearl River Delta 
area reaches 0.9257 , much higher than the linear regression model (Table 2 and Figure 8). Hence, the power-function regression model provides a significant improvement to the linear regression model for the relationship between construction area and resident population. This indicates that, compared to the linear model, the power-function model is more suitable

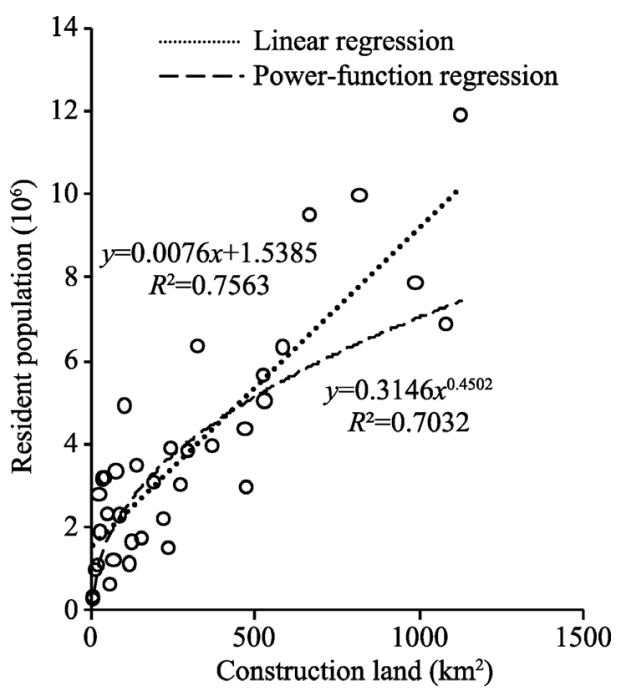

Figure 9 Relationship between resident population and construction area in the Pearl River Delta for describing the relationship between construction area and GDP in the nine cities of the PRD. The regression equation for the power- function model between GDP and construction area in the PRD takes a form of:

$$
y=0.1197 x^{1.1119}
$$

where $y$ is the value of GDP (billion yuan) and $\mathrm{x}$ represents the construction area $\left(\mathrm{km}^{2}\right)$.

In contrast, it can be noticed in Table 2 and Figure 9 that the application of a power-function regression model between the construction area and resident population cannot generate a significant improvement. Although the linear regression model remains suitable for illustrating the relationship, it is necessary to point out that the growth of resident population in the PRD is already subject to the constraints of land resource.

\section{Land resource constraint on resident population growth}

\subsection{Limit of land resource}

Land resource, the material foundation of human survival, provides an indispensable space for inhabitation, transportation and other human activities. Due to the rapid growth of population in the PRD, construction area expanded sharply and the limits of land resource have nearly been reached in some cities. Considering topographical constraints, land with slopes of $10 \%$ or less and elevations of $100 \mathrm{~m}$ or lower is regarded as flatland suitable for development (Ye et al., 2003). We also examined the land use data obtained in this study and the DEM data downloaded from the USGS with the tool of Overlay Analysis in ArcGIS, and found that more than $98 \%$ of the construction land in the region is concentrated in the flatland. Subtracting water area and prime cropland preservation area from the flatland yields the limit of land resource suitable for development for each city in the PRD (Table 3). It can be seen from Table 3 that there is still plenty of flatland suitable for development in the region overall, but more than a half of the flatland is concentrated in Jiangmen, Huizhou and Zhaoqing, where construction areas have been expanding relatively slowly. For the cities expanding at high speeds, such as Shenzhen and Dongguan, construction areas are approaching to the limits.

The distribution of the remaining flatland is also unbalanced in each city of the PRD (Figure 10). Although large areas suitable for development remain in Guangzhou and Zhuhai, most of them are distributed far from the centers of the two cities. As shown in Figure 10, 
the remaining flatland in Guangzhou is concentered in the northeast (Zengcheng District and Conghua District) and the south (Nansha District). In Zhuhai, the remaining flatland is mainly distributed in the west (Doumen District and Jinwan District). As a whole, the supply of new flatland for further development has been lowered down gradually in these cities. In the absence of sufficient suitable land, population density in these cities has gradually approached to saturation. To meet transportation, housing and other needs for urban life, the lowest per capita construction land needs to be approximately $140-200 \mathrm{~m}^{2}$, or $5000-7140$ person $\cdot \mathrm{km}^{-2}$ in population density (Zhou et al., 2003). According to this criterion, Shenzhen and Guangzhou are apparently already over-populated.

Table 3 Distribution of land resource and population in the Pearl River Delta in 2009

\begin{tabular}{lccccccc}
\hline \multicolumn{1}{c}{ City } & $\begin{array}{c}\text { Flatland } \\
\left(\mathrm{km}^{2}\right)\end{array}$ & $\begin{array}{c}\text { Water } \\
\left(\mathrm{km}^{2}\right)\end{array}$ & $\begin{array}{c}\text { Primary } \\
\text { cropland } \\
\left(\mathrm{km}^{2}\right)\end{array}$ & $\begin{array}{c}\text { Limit of land } \\
\text { resource } \\
\left(\mathrm{km}^{2}\right)\end{array}$ & $\begin{array}{c}\text { Construc- } \\
\text { tion land } \\
\left(\mathrm{km}^{2}\right)\end{array}$ & $\begin{array}{c}\text { Non-agricultu } \\
\text { ral population } \\
(\mathrm{million})\end{array}$ & $\begin{array}{c}\text { Population } \\
\text { density } \\
\left(\mathrm{km}^{-2}\right)\end{array}$ \\
\hline Guangzhou & 4310.17 & 447.8 & 1123.45 & 2738.93 & 1125.77 & 11.06 & 9827.55 \\
Shenzhen & 1165.9 & 127.49 & 20.00 & 1018.42 & 817.35 & 9.95 & 12173.61 \\
Zhuhai & 1024.31 & 104.54 & 244.08 & 675.69 & 232.94 & 1.54 & 6618.71 \\
Dongguan & 1961.4 & 206.85 & 279.22 & 1475.33 & 988.52 & 6.89 & 6968.09 \\
Foshan & 3319.85 & 347.4 & 486.63 & 2485.83 & 1082.2 & 5.13 & 4739.78 \\
Zhongshan & 1421.01 & 148.37 & 438.67 & 833.97 & 472.17 & 2.27 & 4809.71 \\
Jiangmen & 5823.99 & 624.74 & 1721.8 & 3477.45 & 466.22 & 2.65 & 5693.02 \\
Huizhou & 4395.16 & 473.49 & 1267.22 & 2654.45 & 367.12 & 2.98 & 8111.52 \\
Zhaoqing & 3589.52 & 379.12 & 1495.11 & 1715.3 & 292.3 & 0.88 & 3007.54 \\
PRD & 27011.32 & 2859.79 & 7076.18 & 17075.36 & 5844.58 & 43.36 & 7418.00 \\
\hline
\end{tabular}

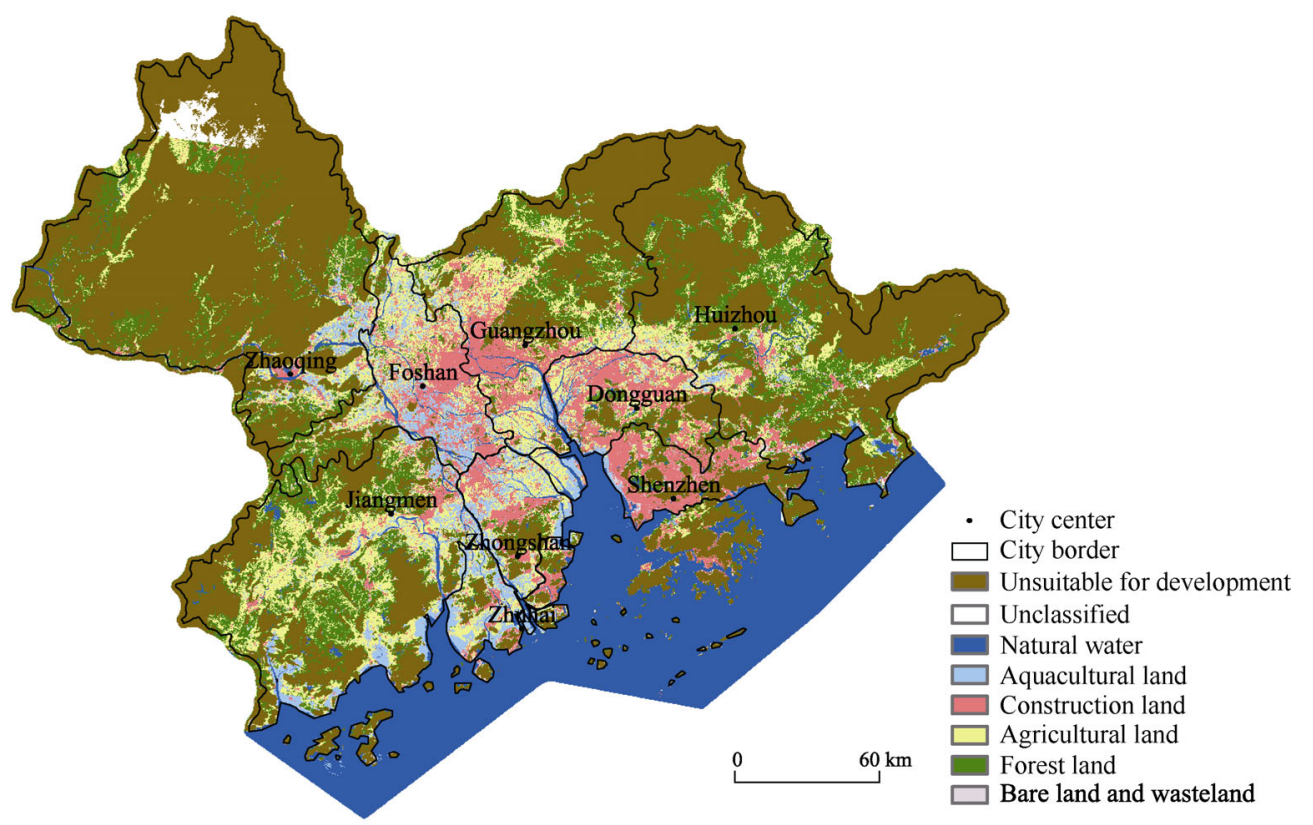

Figure 10 The distribution of remaining flatland in the Pearl River Delta in 2009

It is interesting to note in Eq. (1) that the increase of construction area takes a rate slower than the increase in GDP. Due to the limit of land resource and the associated expansion of 
construction area, land resource suitable for development becomes less and less, leading to the continuous rise of land price, more intensive development of land resource and a higher production per unit construction land. This trend can be clearly seen from the change in the GDP per unit construction land. As shown in Figure 11, the GDP per unit construction land in most cities of the PRD has increased significantly since 1999, with Shenzhen and Guangzhou being the fastest.

\subsection{Resident population change under land resource constraints}

To examine the influence of land resource constraint on population growth in the PRD, both Malthus and Logistic models are ap-

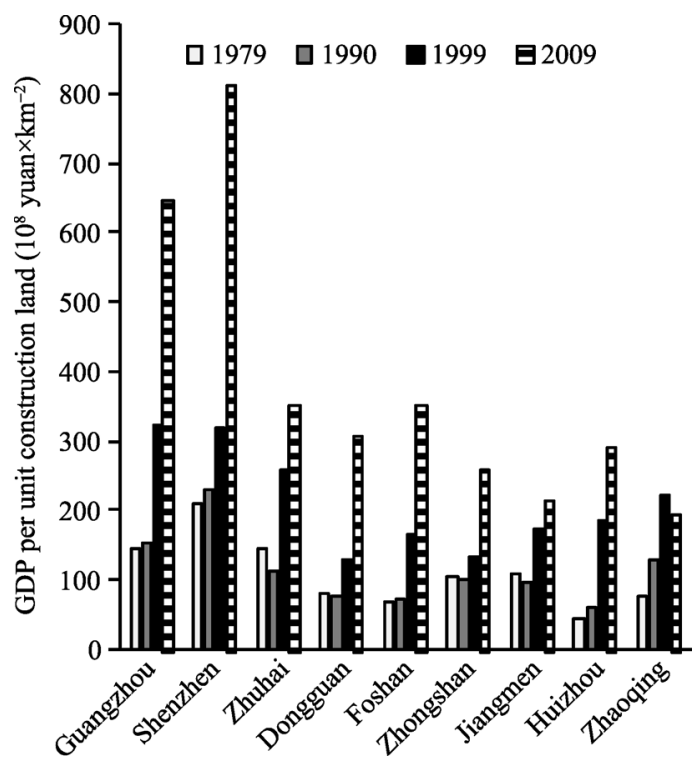

Figure 11 Changes of GDP in unit construction land in each city of the Pearl River Delta plied to illustrate the dynamic change of resident population in each city of the PRD. The Malthus model assumes that population grows exponentially (Malthus, 1798), so the following function is applied:

$$
P=P_{0} e^{r t}
$$

where $t$ represents time, $P_{0}$ is the initial population at $t=0$, and $r$ is an undetermined coefficient associated with the population growth in the concerned field.

Equivalently, Eq. (2) can be transformed into the linear form with a logarithmic transformation:

$$
\ln (P)=\ln \left(P_{0}\right)+r t
$$

By applying the least-squares regression method, parameters $P_{0}$ and $r$ can be obtained from Eq. (3). Under the constraint of physical environment, typically land resource, population growth normally cannot sustain in the exponential form of Eq. (2) in the long term. To address this problem, the Logistic model has been proposed (Verhulst, 1838; Pearl et al., 1920). In the initial stage, the growth of population in the Logistic model is approximately exponential; then as population approaches saturation, its growth slows down gradually and eventually remains almost unchangeable. As a whole, the Logistic model takes an "S"shaped curve, with the equation of:

$$
\hat{y}=\frac{K}{1+\alpha+e^{-\beta t}}, \quad \alpha, \beta>0
$$

where $K$ is a constant representing the upper limit of population growth; $\alpha$ and $\beta$ are both undetermined parameters. By applying a logarithmic transformation, Eq. (4) can be converted into the following form:

$$
\ln \left(\frac{K}{\hat{y}}-1\right)=\ln (\alpha)-\beta t
$$

With Eq. (5) and by assuming that $K$ is known, $\alpha$ and $\beta$ can be determined by using the 
least-squares regression method. The value of $K$ can be determined by using an enumeration method: assigning different values to $K$, calculating the corresponding values of $R^{2}$ and giving the value that maximizes $R^{2}$ to $\mathrm{K}$.

Table 4 presents the results of the population changes for each city in the PRD during 1979-2009 predicted by both Malthus and Logistic models. According to the values of $\mathrm{R}^{2}$ obtained by applying the two models to each city in the PRD, the fit of the Logistic model to the population data is better than the Malthus model except in Zhaoqing (Table 4).

Table 4 Population growth rates obtained from the Malthus and Logistic models in terms of Eqs. (2) and (4) for each city in the Pearl River Delta

\begin{tabular}{|c|c|c|c|c|c|c|}
\hline \multirow{2}{*}{ City } & \multicolumn{2}{|c|}{ Malthus model } & \multicolumn{4}{|c|}{ Logistic model } \\
\hline & Growth rate $(\%)$ & $R^{2}$ & $K$ & $\alpha$ & $\beta$ & $R^{2}$ \\
\hline Guangzhou & 3.12 & 0.9641 & 1450 & 12.3677 & 0.1108 & 0.9700 \\
\hline Shenzhen & 13.12 & 0.9432 & 1090 & 46.3464 & 0.1934 & 0.9941 \\
\hline Zhuhai & 5.78 & 0.9762 & 210 & 6.8164 & 0.0973 & 0.9889 \\
\hline Dongguan & 8.49 & 0.9383 & 830 & 138.8710 & 0.2408 & 0.9696 \\
\hline Foshan & 4.13 & 0.9719 & 810 & 24.8648 & 0.1444 & 0.9855 \\
\hline Zhongshan & 4.24 & 0.9595 & 360 & 21.5043 & 0.1346 & 0.9715 \\
\hline Jiangmen & 1.08 & 0.9942 & 480 & 9.5208 & 0.1059 & 0.9967 \\
\hline Huizhou & 2.90 & 0.9848 & 1080 & 3.2335 & 0.0780 & 0.9970 \\
\hline Zhaoqing & 0.93 & 0.9726 & 460 & 4.8575 & 0.0659 & 0.9658 \\
\hline
\end{tabular}

In addition, it can be seen from Table 4 that the Logistic model yields more accurate predictions of population growth than the Malthus model. Based on our collected demographic statistics for the PRD during 2010-2012, the errors between the actual data and the predictions of population growth using the Logistic model are generally smaller except in Zhuhai (Figure 12). By 2020, the predictions of population growth with the Logistic model are still in an acceptable range, while the predictions with the Malthus model significantly fall far away from the acceptable range, typically in Shenzhen and Dongguan. According to the

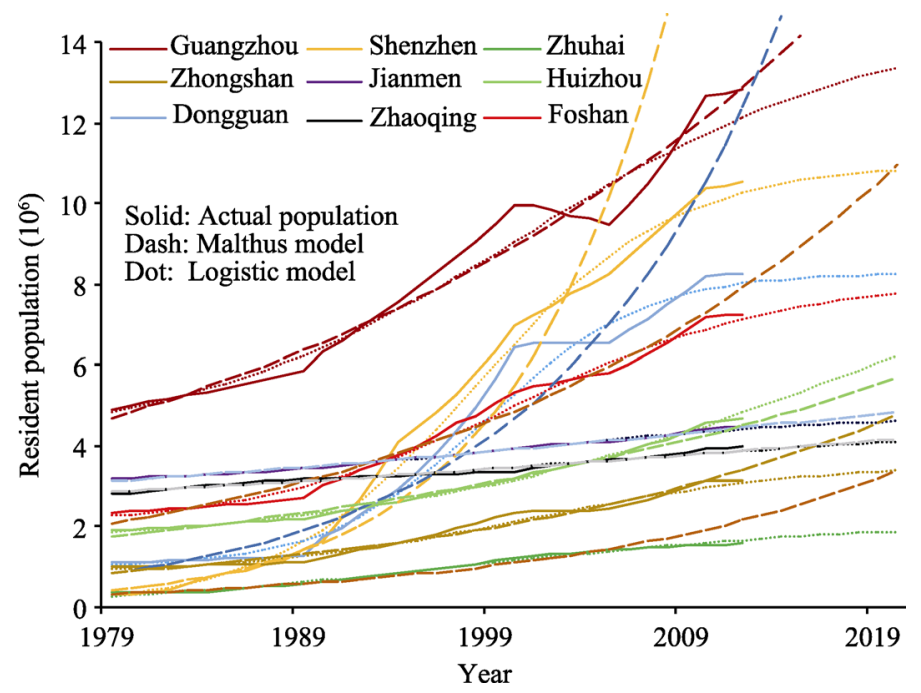

Figure 12 Predictions of both Malthus and Logistic models against statistical data for each city in the Pearl River Delta 
Malthus model, the population of Shenzhen will reach more than 60 million before 2020, which obviously exceeds the population carrying capacity of Shenzhen.

However, the difference between the predictions with both Logistic and Malthus models is very small prior to 2000. In fact, the two curves of population growth predicted with the two models for each city are essentially coincident before 2005 except for Shenzhen and Dongguan (Figure 12). In the early phase of population growth, the constraint of land resource on population growth is not significant, so the population growth is approximately exponential; as the population approaches the limit of land resource, the Logistic model yields a slower growth of population and the difference between the predictions from the models becomes larger and larger.

For cities subject to the severe constraint of land resource, the significant difference between the predictions from the two models arises earlier. For example, the difference between the predictions from the two models became larger and larger since 2003 in Shenzhen, while such a change in the difference arose later in Dongguan and Guangzhou. In other cities subject to the less server constraint of land resource, such as Zhuhai, Foshan and Zhongshan, the significant difference in the population predictions arose even later and was more inconspicuous. In cities with relatively abundant land resource, including Jiangmen, Huizhou and Zhaoqing, there was no significant difference between the population predictions from both Malthus and Logistic models.

\section{Discussion and conclusions}

\subsection{Discussion}

Since 1979, the PRD has undergone tremendous changes in economy, population and land use. A detailed analysis of the regional economic and demographic data from 1979 to 2009 reveals that the economic growth in the PRD is related to the growth of resident population in a complex form. Before 2000, an increase of one million resident population corresponded to an increase of approximately 32 billion yuan in GDP, whereas after 2000, the same increase in resident population corresponded to an increase of approximately 162 billion yuan in GDP.

By applying a linear regression method, it is found that the change in the regional construction area during 1979-2009 is linearly linked significantly with GDP and resident population in all nine cities of the PRD. According to these linear regressions, $1 \mathrm{~km}^{2}$ of the construction area expansion can make the regional GDP increase by approximately 0.4761 billion yuan and the resident population grow by approximately 7600 . However, the rapid expansion of construction area over the course of more than 30 years has approached the limits of land resource in some cities of the PRD and the constraint of land resource has made the linear relationships between construction land, GDP and resident population change into nonlinear forms.

In the early developmental stage of the PRD, land resource was abundant and it is found that the expansion of construction area contributes to economic growth in a linearly proportional form. When the limit of land resource was approached, the expansion of construction area took a slower pace, while the GDP per unit area of construction area increased still at a much faster speed. This made a power function more suitable than a linear one in illustrating the relationship between GDP and construction area. 
In parallel with the change in GDP per unit area, population density in the PRD also increased under the constraint of land resource. However, the population density cannot grow indefinitely in consideration of the suitability of living. Hence, there is an upper limit of population growth for each city. In some cities where most of land resource has been urbanized, such as Shenzhen and Dongguan, their populations are close to their limits and their population growths have been slowing down. As a result, the Logistic model is able to provide more accurate predictions of population growth than the Malthus model in these cities.

Due to the unbalanced economic development, there are large differences in the pressures of land resource in the nine cities of the PRD, making the relationships between economy, population and construction land exhibit different characteristics in different cities. For the six cities in the central region of the PRD, including Guangzhou, Shenzhen, Dongguan, Foshan, Zhuhai and Zhongshan, the GDP per unit construction area increased significantly at the later stage. Consequently, the linear relationship between economy and the construction area has been gradually weakening. Under the constraint of land resource, the population growth in these cities has been gradually slowing down, making the Logistic model more suitable to predict the population growth in the region. In the eastern and western parts of the PRD, including Huizhou, Jiangmen and Zhaoqing, the economic growth is still depending on land resource and the linear relationship between economy and the construction land is maintained. Due to the small pressures of land resource in Huizhou, Jiangmen and Zhaoqing, the Malthus model is suitable for the population prediction of the three cities.

\subsection{Conclusions}

In this paper, a quantitative analysis on the four phases of the regional land use data extracted from remote sensing images and socioeconomic statistics spanning 1979 to 2009 is applied to reveal the spatiotemporal characteristics of construction area expansion in relation to economic-demographic development and land resource in the PRD. The results showed that: (1) From 1979 to 2009, the proportion of construction area in the PRD increased from $0.5 \%$ in 1979 to $10.8 \%$ in 2009 , accompanied with a rapid loss of agricultural land. (2) According to the linear regressions, each $\mathrm{km}^{2}$ of the construction area expansion can make the regional GDP increase by approximately 0.4761 billion yuan and the resident population grow by approximately 7600. (3) Constrained by the limits of land resource in some cities of the PRD, a power function is more suitable than a linear one in describing the relationship between GDP and construction area, while the Logistic model provides more accurate predictions of population growth than the Malthus model in some cities where a very large proportion of land resource has been urbanized, such as Shenzhen and Dongguan.

\section{References}

Bertinelli L, Black D, 2004. Urbanization and growth. Journal of Urban Economics, 56(1): 80-96.

Bettencourt L M A, 2013. The origins of scaling in cities. Science, 340(6139): 1438-1441.

Chang G H, Brada J C, 2006. The paradox of China's growing under-urbanization. Economic Systems, 30(1): 24-40.

Chen $\mathrm{Na}, 2008$. Study on the interactive relationship between migrant labor and economic development of the Pearl River Delta [D]. Guangzhou: Jinan University. (in Chinese)

Chen Yanguang, 2011. Modelling the relationships between urbanization and economic development levels with three functions. Scientia Geographica Sinica, 31(1): 1-6. (in Chinese)

Cheng Kaiming, 2007. A review of the mechanism and theoretical models on urbanization and economic growth. Economic Review, 28(4): 143-150. (in Chinese) 
Davis K, 1966. The Urbanization of the Human Population. The City Reader. New York: Routledge, 1-14.

Deng Shiwen, Yan Xiaopei, Zhu Jincheng, 1999. Growth of urban and town construction land in the Pearl River Delta. Economic Geography, 19(4): 80-84. (in Chinese)

Deng Xiangzheng, Huang Jikun, Rozelle S et al., 2008. Growth, population and industrialization, and urban land expansion of China. Journal of Urban Economics, 63(1): 96-115.

Fay M, Opal C, 2000. Urbanization without Growth: A Not So Uncommon Phenomenon. Vol. 2412. New York: World Bank Publications.

Filatova T, Parker D, van der Veen A, 2009. Agent-based urban land markets: Agent's pricing behavior, land prices and urban land use change. The Journal of Artificial Societies and Social Simulation, 12(1): 1-31.

General Administration of Quality Supervision, Inspection and Quarantine of the People's Republic of China and Standardization Administration of the Peoples Republic of China. 2007. Current Land Use Classification GB/T21010-2007. (in Chinese)

Hance W A, 1970. Population, Migration, and Urbanization in Africa. Vol. 70: New York: Columbia University Press.

Henderson V, 2003. The urbanization process and economic growth: The so-what question. Journal of Economic Growth, 8(1): 47-71.

Hu Angang, 2003. Urbanization is the next major driver force of China's economic development. Chinese Journal of Population Science, 17(6): 5-12. (in Chinese)

Li Xia, Yeh A G O, 2000. Modelling sustainable urban development by the integration of constrained cellular automata and GIS. International Journal of Geographical Information Science, 14(2): 131-152.

Liu Jiyuan, Zhan Jinyan, Deng Xiangzheng, 2005. Spatio-temporal patterns and driving forces of urban land expansion in China during the economic reform era. AMBIO: A Journal of the Human Environment, 34(6): $450-455$.

Malthus T R, 1798. An Essay on the Principle of Population 1998. Vol. 1. London: Electronic Scholarly Publishing Project.

Moomaw R L, Shatter A M, 1996. Urbanization and economic development: A bias toward large cities? Journal of Urban Economics, 40(1): 13-37.

Ottensmann J R, 1977. Urban sprawl, land values and the density of development. Land Economics, 53(4): 389-400.

Oucho J O, Gould W T, 1993. Internal Migration, Urbanization, and Population Distribution. Demographic Change in Sub-Saharan Africa. Washington, D.C.: National Academy Press, 256-296.

Pearl R, Reed L J, 1920. On the rate of growth of the population of the United States since 1790 and its mathematical representation. Proceedings of the National Academy of Sciences of the United States of America, 6(6): 275.

Portugali J, 2000. Self-Organization and the City. Berlin: Springer.

Sato Y, Yamamoto K, 2005. Population concentration, urbanization, and demographic transition. Journal of Urban Economics, 58(1): 45-61.

Seto K C, Kaufmann R K, 2003. Modeling the drivers of urban land use change in the Pearl River Delta, China: Integrating remote sensing with socioeconomic data. Land Economics, 79(1): 106-121.

Seto K C, Fragkias M, Güneralp B et al., 2011. A meta-analysis of global urban land expansion. PLoS ONE, 6(8): $1-9$.

Shen K R, Jiang R, 2007. How does urbanization affect economic growth in China. Statistical Research, 24(6): 9-15. (in Chinese)

Tan Minghong, Li Xiubing, Lv Changhe, 2003. An analysis of driving forces of urban land expansion in China Economic Geography, 23(5): 635-639.

USGS, 2012. Usgs Global Visualization Viewer. http://glovis.usgs.gov/, 2012-05-17.

Verhulst P-F, 1838. Notice Sur La Loi Que La Population Suit Dans Son Accroissement. Correspondance Mathématique et Physique Publiée Par A. Quetelet, 10: 113-121.

World Resources Institute UNEP, United Nations Development Programme, the World Bank, 1996. World Resources 1996-97: The Urban Environment: New York.

Yang H S, 1995. An investigation and analysis on laborer tide in Pearl River Delta. Population Research, 19(02): 53-56. (in Chinese)

Ye Yuyao, Li Xiaobing, Zhang Hongou, 2008. Limits on construction land use in the Pearl River Delta. Resources Science, 30(5): 683-687. (in Chinese)

Zhou Chun, Shu Tingfei, Wu Renhai, 2003. A study of carrying capacity of land resources in Pearl River Delta. Scientific and Technological Management of Land and Resources, 20(6). (in Chinese)

Zhou Yixing, 1982. A research on the relationship between GNP and urbanization. Population \& Economics, 3(1): 28-33. (in Chinese) 